\title{
Influence of Scandium Addition on Stress Corrosion Cracking Susceptibility of Al-Zn-Mg Alloy in Different Corrosive Environments
}

\author{
Zhaoming Li ${ }^{1,2}$, Haichang Jiang ${ }^{1, *}$, Desheng Yan ${ }^{1}$ and Lijian Rong ${ }^{1, *}$ \\ 1 CAS Key Laboratory of Nuclear Materials and Safety Assessment, Institute of Metal Research, \\ Chinese Academy of Sciences, Shenyang 110016, China; zmli14b@imr.ac.cn (Z.L.); dsyan@imr.ac.cn (D.Y.) \\ 2 University of Chinese Academy of Sciences, 19 Yuquan Road, Beijing 100049, China \\ * Correspondence: hcjiang@imr.ac.cn (H.J.); ljrong@imr.ac.cn (L.R.); Tel.: +86-024-2397-1985 (H.J.); \\ +86-024-2397-1979 (L.R.)
}

Received: 14 February 2018; Accepted: 28 March 2018; Published: 29 March 2018

\begin{abstract}
Stress corrosion cracking (SCC) susceptibilities of Al-Zn-Mg alloys without and with Scandium addition were evaluated in $3.5 \% \mathrm{NaCl}$ solution at different $\mathrm{pH}$ and different strain rate, using slow strain rate test technique. The results indicate that $\mathrm{Sc}$ addition reduces grain size and width of precipitation free zones, and transforms grain boundary precipitates from continuous distribution into interrupted distribution by inhibiting recrystallization. In solution at $\mathrm{pH} 1, \mathrm{pH} 3$ and $\mathrm{pH} \mathrm{7,} \mathrm{Sc} \mathrm{addition} \mathrm{reduces} \mathrm{the} \mathrm{degree} \mathrm{of} \mathrm{localized} \mathrm{corrosion} \mathrm{of} \mathrm{alloy} \mathrm{surface} \mathrm{and} \mathrm{SCC} \mathrm{susceptibility} \mathrm{of}$ $\mathrm{Al}-\mathrm{Zn}-\mathrm{Mg}$ alloy. However, in solution at $\mathrm{pH} 10$ and $\mathrm{pH}$ 12, grain refinement significantly promotes the diffusion of hydrogen atoms into matrix, thus Sc addition increases SCC susceptibility of Al-Zn-Mg alloy. Under different strain rate conditions, Sc addition can all reduce SCC susceptibility of Al-Zn-Mg alloy in solution at $\mathrm{pH} 1, \mathrm{pH} 3$ and $\mathrm{pH}$ 7, and can all increase SCC susceptibility of $\mathrm{Al}-\mathrm{Zn}-\mathrm{Mg}$ alloy in solution at $\mathrm{pH} 10$ and $\mathrm{pH}$ 12. As a result, Sc modified $\mathrm{Al}-\mathrm{Zn}-\mathrm{Mg}$ alloy in practical applications should be avoided in alkaline environments.
\end{abstract}

Keywords: Al-Zn-Mg alloy; solution $\mathrm{pH}$; strain rate; stress corrosion cracking susceptibility

\section{Introduction}

The age-hardenable 7xxx series $\mathrm{Al}$ alloys can be divided into medium strength $\mathrm{Al}-\mathrm{Zn}-\mathrm{Mg}$ system and high strength $\mathrm{Al}-\mathrm{Zn}-\mathrm{Mg}-\mathrm{Cu}$ system [1-6]. Nowadays, 7xxx series alloys are being used in the aerospace and high-speed train system for structural components due to their high strength/weight ratio [7-12]. 7xxx series alloys are mainly applied in the form of rolled plates or extruded sections, and the static or dynamic recrystallization is easy to occur during hot working and heat treatment. Compared with low-angle grain boundary, high-angle recrystallization grain boundary with higher grain boundary energy promotes the nucleation and growth of grain boundary precipitates (GBPs) [13]. Under peak-aged condition, the GBPs distributed continuously along recrystallization grain boundary accelerate corrosion crack propagation $[14,15]$. Thus, the peak-aged 7xxx series alloys possess high strength but poor stress corrosion cracking (SCC) resistance. Overaging heat treatment can enhance SCC resistance but strength decreases by $10 \%$ to $15 \%$ in comparison to the peak-aged condition. With the improved requirements of industrial equipment and components on comprehensive properties, how to inhibit recrystallization and increase strength and SCC resistance of $7 x x x$ series alloys has become a research hotspot.

In recent years, modification effect of Scandium on $\mathrm{Al}$ alloys has been extensively studied. It was confirmed that Sc addition can significantly improve strength and SCC resistance of 7xxx series alloys [16-22]. For example, Kannan et al. [17] reported the addition of Sc into $7010 \mathrm{Al}$ alloys 
could introduce a large number of nanosized $\mathrm{Al}_{3}(\mathrm{Sc}, \mathrm{Zr})$ phases to strengthen the alloy and inhibit recrystallization, at the same time, SCC susceptibility of the alloy in neutral $3.5 \% \mathrm{NaCl}$ solution was reduced. Deng et al. [18] showed that the additions of Sc and Zr improved the tensile properties of $\mathrm{Al}-\mathrm{Zn}-\mathrm{Mg}$ alloy and increased the resistance to SCC in neutral 3.5\% $\mathrm{NaCl}$ solution due to refining grain size and restraining the formation of precipitation free zones (PFZ) by inhibiting recrystallization.

The results of literature survey indicate that the previous studies about the effect of Sc on the SCC susceptibilities of 7xxx series alloys are generally carried out in neutral $\mathrm{NaCl}$ solution. In fact, changes in service conditions of structural components may cause localized acidic or alkaline environment. Besides, fluctuating tensile stress during the application process can lead to the variation of strain rate. Solution $\mathrm{pH}$ or strain rate can notably affect the SCC process of 7xxx series alloys [23,24]. However, it is still unknown whether Sc addition can enhance the SCC resistance of 7xxx series alloys under different environmental conditions. In the 7xxx series family, high strength Al- $\mathrm{Zn}-\mathrm{Mg}-\mathrm{Cu}$ alloy is non-weldable, while medium strength Al-Zn-Mg alloy is weldable due to the absence of copper gives a good resistance to hot cracking during the weld cooling [25]. Therefore, medium strength $\mathrm{Al}-\mathrm{Zn}-\mathrm{Mg}$ alloy is particularly suited when welding is necessary. In this work, two kinds of $\mathrm{Al}-\mathrm{Zn}-\mathrm{Mg}$ alloys without and with Sc addition were applied. The effect of Sc addition on SCC susceptibility of $\mathrm{Al}-\mathrm{Zn}-\mathrm{Mg}$ alloy in 3.5\% $\mathrm{NaCl}$ solution at different $\mathrm{pH}$ and different strain rate is systematic studied, to provide theoretical and experimental basis for engineering design and application of Sc modified Al-Zn-Mg alloy.

\section{Materials and Methods}

Two kinds of Al-Zn-Mg alloys without and with Sc additions were prepared by an electrical resistance furnace, and their chemical compositions are shown in Table 1. Al-Zn-Mg castings were firstly homogenized at $470{ }^{\circ} \mathrm{C}$ for $24 \mathrm{~h}$, then hot extruded at $450{ }^{\circ} \mathrm{C}$ to get rectangular plates with a cross section of $35 \mathrm{~mm}$ in width $\times 17 \mathrm{~mm}$ in thickness, followed by water quenching. The sheets were placed in ambient environment for $72 \mathrm{~h}$, then were aged at $100{ }^{\circ} \mathrm{C}$ for $12 \mathrm{~h}+160{ }^{\circ} \mathrm{C}$ for $8 \mathrm{~h}$.

Table 1. Chemical compositions of the experimental alloys (wt \%).

\begin{tabular}{lcccccccc}
\hline Alloys & Zn & Mg & Mn & Cr & Sc & Zr & Ti & Al \\
\hline $0.00 S c$ & 4.19 & 1.36 & 0.32 & 0.21 & - & 0.10 & 0.06 & Bal. \\
$0.06 S c$ & 4.08 & 1.35 & 0.30 & 0.19 & 0.06 & 0.11 & 0.06 & Bal. \\
\hline
\end{tabular}

The microstructures of the aged plates were observed by optical microscopy (Olympus, Tokyo, Japan) and transmission electron microscopy (Jeol, Tokyo, Japan). Thin foils for TEM analysis were prepared by twin-jet polishing at $14 \mathrm{~V}$ in an electrolyte solution composed of $30 \%$ nitric acid and $70 \%$ methanol solution cooled to $-25{ }^{\circ} \mathrm{C}$.

SCC susceptibility was evaluated using the slow strain rate test (SSRT). SSRT was carried out in air and in $3.5 \% \mathrm{NaCl}$ solution at different $\mathrm{pH}$. Solution $\mathrm{pH}$ value was adjusted by adding a moderate amount of analytical grades $\mathrm{HCl}$ and $\mathrm{NaOH}$ to $3.5 \% \mathrm{NaCl}$ solution. The long axis of SSRT specimens was parallel to extrusion direction, and the gauge size was $30 \mathrm{~mm} \times 6 \mathrm{~mm}$ with a thickness of $3 \mathrm{~mm}$. Each test was repeated at least two times in order to ensure reproducibility of the measurements. The SCC susceptibility was calculated by the following equation:

$$
I_{\mathrm{SCC}}=\left(1-\delta_{\mathrm{sol}} / \delta_{\mathrm{air}}\right) \times 100 \%,
$$

where $\delta_{\text {air }}$ and $\delta_{\text {sol }}$ were the elongation in air and in corrosive solution, respectively. The large $I_{\text {SCC }}$ reveals the poor SCC resistance.

Potentiodynamic polarization experiments were carried out using electrochemical workstation (Gamry, Warminster, PA, USA). A platinum foil and a saturated calomel electrode (SCE) were used as counter electrode and reference electrode, respectively, while $1 \mathrm{~cm}^{2}$ area of the studied alloy served as 
the working electrode. Experiments were repeated two times in aerated $3.5 \% \mathrm{NaCl}$ solution at different $\mathrm{pH}$ with a scan rate of $1 \mathrm{mV} \cdot \mathrm{s}^{-1}$. Further, $8 \mathrm{~mm}$ long samples were cut close to fracture surface of SSRT specimens as illustrated in Figure 1, then analyzed by RHEN602 inert gas fusion analyzer (Leco, Saint Joseph, MI, USA) for determining hydrogen concentration near fracture location.

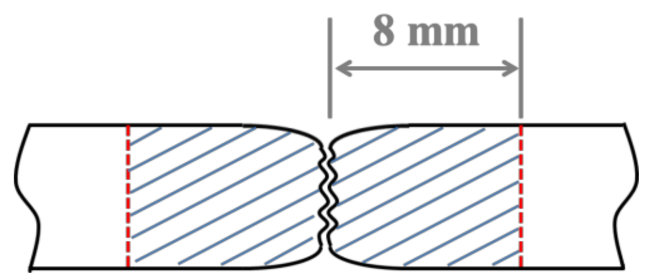

Figure 1. Sampling location of $8 \mathrm{~mm}$ long sample for hydrogen analysis.

\section{Results}

\subsection{The Microstructures of Al-Zn-Mg Alloys without and with Sc Addition}

Figure 2 shows the microstructures of two aged alloys, and the microstructural difference between two kinds of Al-Zn-Mg alloys can be easily found. The microstructure of 0.00Sc alloy consists of high volume fraction of recrystallized grains (Figure 2a), while the microstructure of 0.06Sc alloy is composed of full fiber-like structure (Figure 2b). In general, interior of fiber-like structure contains a larger number of subgrains, thus Sc addition can significantly reduce grain size of Al-Zn-Mg alloy. TEM observation of grain boundary microstructure indicates that $0.00 \mathrm{Sc}$ alloy exhibits a continuously distributed GBPs and wide PFZ (Figure 2c), but 0.06Sc alloy shows a discontinuously distributed GBPs and narrow PFZ, and the nano-sized $\mathrm{Al}_{3}(\mathrm{Sc}, \mathrm{Zr}$ ) phase exists in the matrix (Figure 2d). Due to the pinning effect of nano-sized $\mathrm{Al}_{3}(\mathrm{Sc}, \mathrm{Zr})$ particles on the movement of the grain boundaries [26], dynamic recrystallization of $\mathrm{Al}-\mathrm{Zn}-\mathrm{Mg}$ alloy during hot extrusion is inhibited. Compared with high-angle recrystallization grain boundary, low-angle subgrain boundary with lower grain boundary energy inhibits the formation of GBPs and PFZ [13], so Sc addition reduces the width of PFZ and transforms GBPs from continuous distribution into interrupted distribution for Al-Zn-Mg alloy.
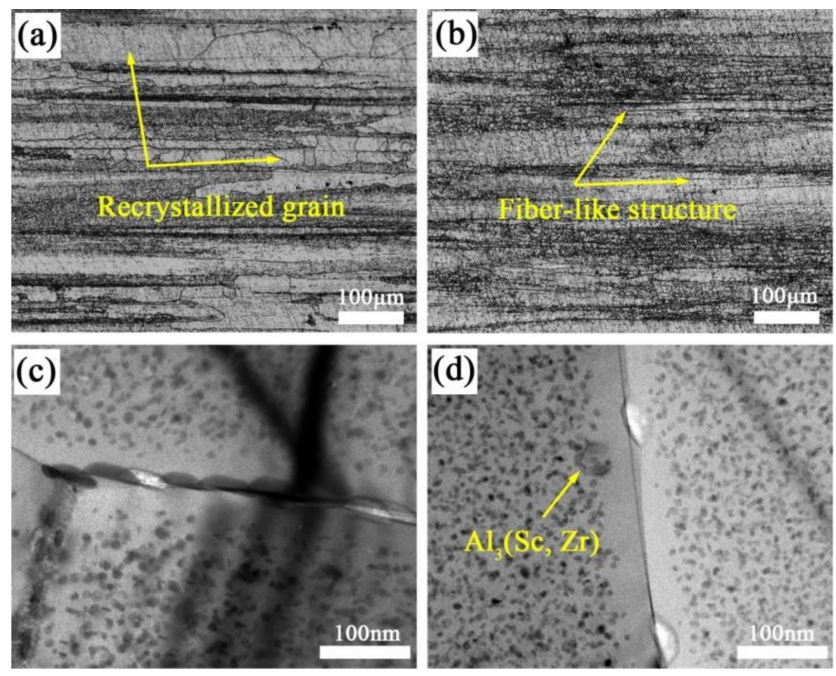

Figure 2. Microstructures of two aged alloys: (a) optical microscopy (OM) image, 0.00Sc; (b) OM image, $0.06 \mathrm{Sc}$; (c) transmission electron microscopy (TEM) image, 0.00Sc; (d) TEM image, $0.06 \mathrm{Sc}$. 


\subsection{SCC Susceptibilities of Al-Zn-Mg Alloys without and with Sc Addition in Solution at Different pH}

Figure 3 gives stress-strain curves of two aged alloys tested at a strain rate of $5 \times 10^{-6} \mathrm{~s}^{-1}$ in different corrosive environments. Compared with the elongation of the specimen tested in air, the elongation of the specimen tested in $3.5 \% \mathrm{NaCl}$ solution at different $\mathrm{pH}$ is lower in the two experimental alloys, indicating that two aged alloys both show tendency to SCC. The corresponding tensile properties such as ultimate tensile strength (UTS), elongation to fracture $\left(E_{\mathrm{f}}\right)$ and $I_{\mathrm{SCC}}$ calculated according to Equation (1) are given in Table 2. From the SSRT results of two aged alloys tested in air, $0.06 \mathrm{wt} \% \mathrm{Sc}$ addition can significantly strengthen Al-Zn-Mg alloy, UTS increases from $364 \mathrm{MPa}$ to $381 \mathrm{MPa}$, and $E_{\mathrm{f}}$ increases from $14.7 \%$ to $15.1 \%$. In addition, two aged alloys in acidic or alkaline corrosive environment both have larger SCC susceptibility in comparison to neutral $3.5 \% \mathrm{NaCl}$ solution, which means that acidic or alkaline corrosive environment aggravates SCC of Al- $\mathrm{Zn}-\mathrm{Mg}$ alloy. In contrast to SCC sensitivities of two aged alloys in $3.5 \% \mathrm{NaCl}$ solution at different $\mathrm{pH}$, it is observed that Sc addition decreases the SCC susceptibility of Al-Zn-Mg alloy in neutral and acidic corrosive environments, while increases the SCC susceptibility in alkaline solution at pH 10 and pH 12.
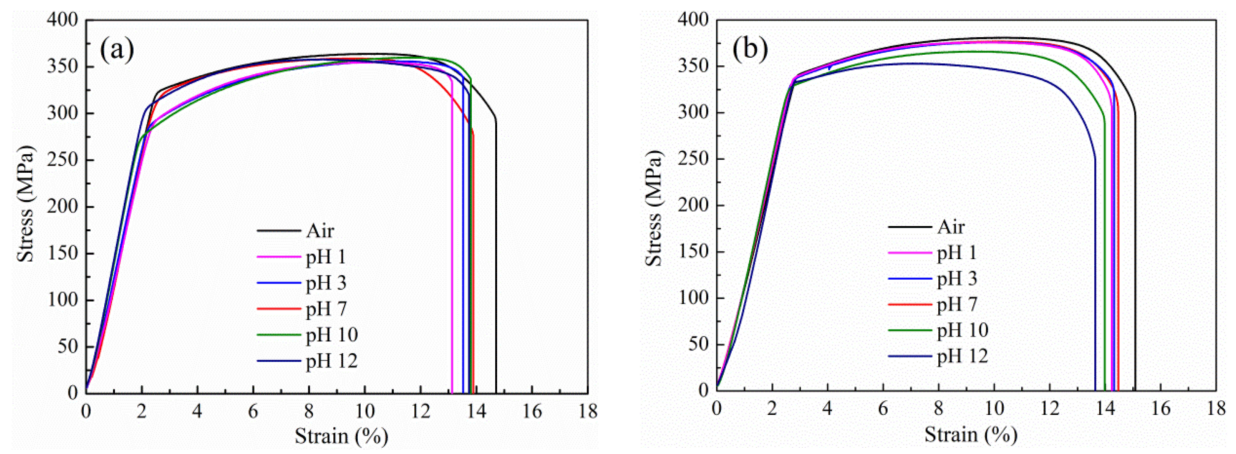

Figure 3. Stress-strain curves of two aged alloys at a strain rate of $5 \times 10^{-6} \mathrm{~s}^{-1}$ in different corrosive environments: (a) $0.00 \mathrm{Sc}$; (b) 0.06Sc.

Table 2. Slow strain rate test (SSRT) results of two aged alloys at a strain rate of $5 \times 10^{-6} \mathrm{~s}^{-1}$ in different corrosive environments.

\begin{tabular}{ccccccc}
\hline \multirow{2}{*}{$\begin{array}{c}\text { Corrosive } \\
\text { Environments }\end{array}$} & \multicolumn{2}{c}{ UTS (MPa) } & \multicolumn{2}{c}{$\boldsymbol{E}_{\mathbf{f}}(\mathbf{\%})$} & \multicolumn{2}{c}{$\boldsymbol{I}_{\text {SCC }}$ (\%) } \\
\cline { 2 - 7 } & $\mathbf{0 . 0 0 S c}$ & $\mathbf{0 . 0 6 S c}$ & $\mathbf{0 . 0 0 S c}$ & $\mathbf{0 . 0 6 S c}$ & $\mathbf{0 . 0 0 S c}$ & $\mathbf{0 . 0 6 S c}$ \\
\hline Air & $364 \pm 4$ & $381 \pm 3$ & $14.7 \pm 0.3$ & $15.1 \pm 0.3$ & - & - \\
pH 1 & $355 \pm 5$ & $376 \pm 1$ & $13.1 \pm 0.2$ & $14.2 \pm 0.3$ & $10.7 \pm 0.6$ & $5.6 \pm 1.0$ \\
pH 3 & $356 \pm 2$ & $376 \pm 3$ & $13.5 \pm 0.2$ & $14.3 \pm 0.2$ & $8.0 \pm 0.5$ & $5.1 \pm 0.8$ \\
pH 7 & $359 \pm 5$ & $377 \pm 5$ & $13.9 \pm 0.2$ & $14.5 \pm 0.1$ & $5.6 \pm 0.9$ & $4.1 \pm 0.3$ \\
pH 10 & $360 \pm 6$ & $366 \pm 2$ & $13.8 \pm 0.2$ & $14.0 \pm 0.2$ & $6.2 \pm 0.7$ & $7.4 \pm 0.4$ \\
pH 12 & $358 \pm 3$ & $353 \pm 6$ & $13.7 \pm 0.1$ & $13.6 \pm 0.2$ & $6.6 \pm 0.4$ & $9.6 \pm 1.0$ \\
\hline
\end{tabular}

Figure 4 shows the surface morphologies of two aged alloys failed at a strain rate of $5 \times 10^{-6} \mathrm{~s}^{-1}$ in $3.5 \% \mathrm{NaCl}$ solution at different $\mathrm{pH}$. When the $\mathrm{pH}$ value of $3.5 \% \mathrm{NaCl}$ solution is less than or equal to 10 , Sc addition can reduce the degree of localized corrosion of $\mathrm{Al}-\mathrm{Zn}-\mathrm{Mg}$ alloy surface. In solution at $\mathrm{pH} 12$, there is no obvious difference in the corrosion morphologies of 0.00Sc alloy and 0.06Sc alloy. 

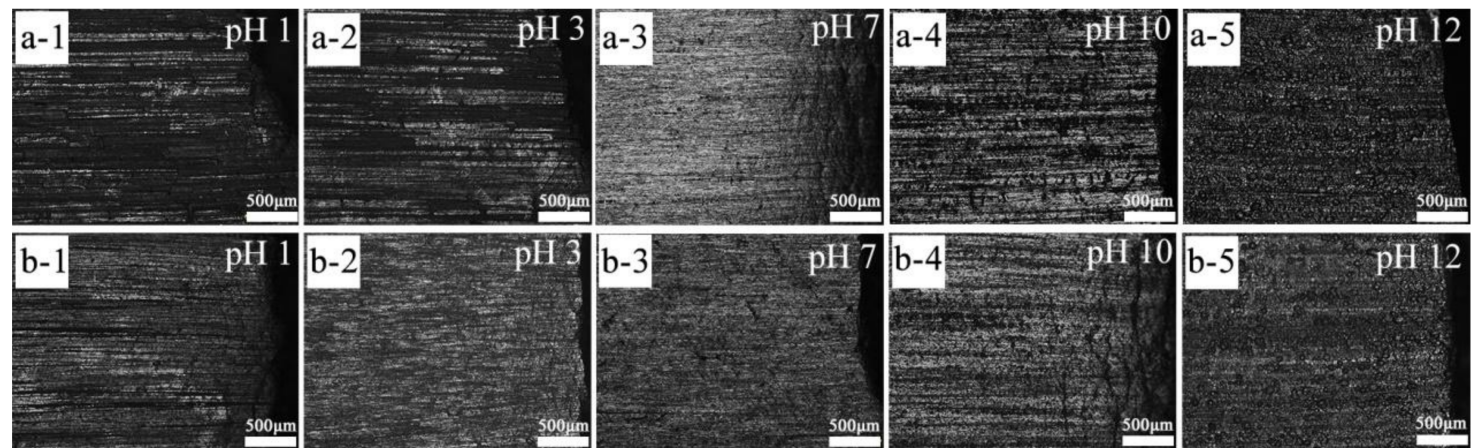

Figure 4. Surface morphologies of SSRT specimens failed at a strain rate of $5 \times 10^{-6} \mathrm{~s}^{-1}$ in $3.5 \% \mathrm{NaCl}$ solution at different $\mathrm{pH}$ : (a) $0.00 \mathrm{Sc}$; (b) $0.06 \mathrm{Sc}$.

\subsection{SCC Susceptibilities of Al-Zn-Mg Alloys without and with Sc Addition at Different Strain Rate}

Based on SSRT results, the SCC susceptibility at different strain rates can be calculated. Figure 5 shows the variation of SCC susceptibilities of two aged alloys in neutral $3.5 \% \mathrm{NaCl}$ solution with strain rate. Two kinds of Al-Zn-Mg alloys both exhibit lower SCC susceptibility when strain rate is too low or too high. It can be seen that $0.00 \mathrm{Sc}$ alloy shows relatively large SCC susceptibility in the strain rate range of $1 \times 10^{-6}-8 \times 10^{-6} \mathrm{~s}^{-1}$, ISCC is around $6.5 \%$, while $0.06 \mathrm{Sc}$ alloy only shows relatively large SCC susceptibility at a strain rate of $5 \times 10^{-6} \mathrm{~s}^{-1}, I_{\mathrm{SCC}}$ is around $4 \%$. Therefore, Sc addition can decrease the SCC susceptibility and relatively susceptible strain rate range to SCC of Al-Zn-Mg alloy in neutral $3.5 \% \mathrm{NaCl}$ solution.

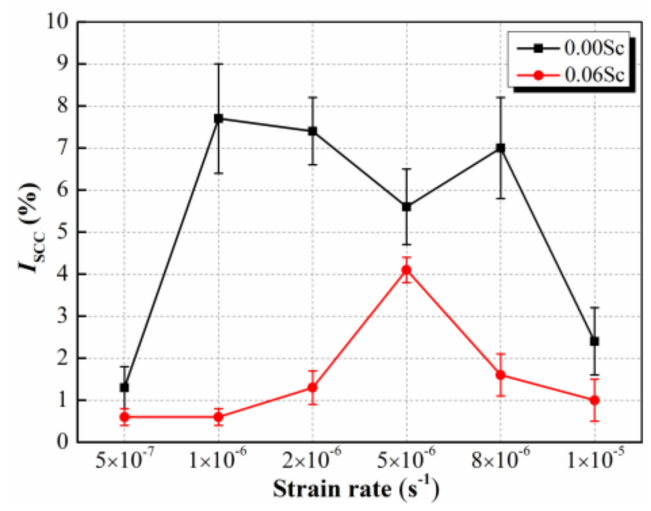

Figure 5. Stress corrosion cracking (SCC) susceptibilities of two aged alloys at different strain rate in neutral $3.5 \% \mathrm{NaCl}$ solution.

In $3.5 \% \mathrm{NaCl}$ solution at different $\mathrm{pH}, \mathrm{SCC}$ susceptibilities of two aged alloys at different strain rate is shown in Figure 6. In acidic or alkaline environment, SCC susceptibility of Al-Zn-Mg alloy is inversely proportional to strain rate, i.e., the slow strain rate leads to high SCC susceptibility. For instance, in solution at pH 12, SCC susceptibility of $0.06 \mathrm{Sc}$ alloy increases from $19.7 \%$ to $33.4 \%$ when reduces the strain rate from $1 \times 10^{-6} \mathrm{~s}^{-1}$ to $5 \times 10^{-7} \mathrm{~s}^{-1}$. Besides, at different strain rate, Sc addition all can decrease SCC susceptibility of Al-Zn-Mg alloy in acidic solution at $\mathrm{pH} 1$ and $\mathrm{pH} 3$, and increase SCC susceptibility in alkaline solution at $\mathrm{pH} 10$ and $\mathrm{pH} 12$. 

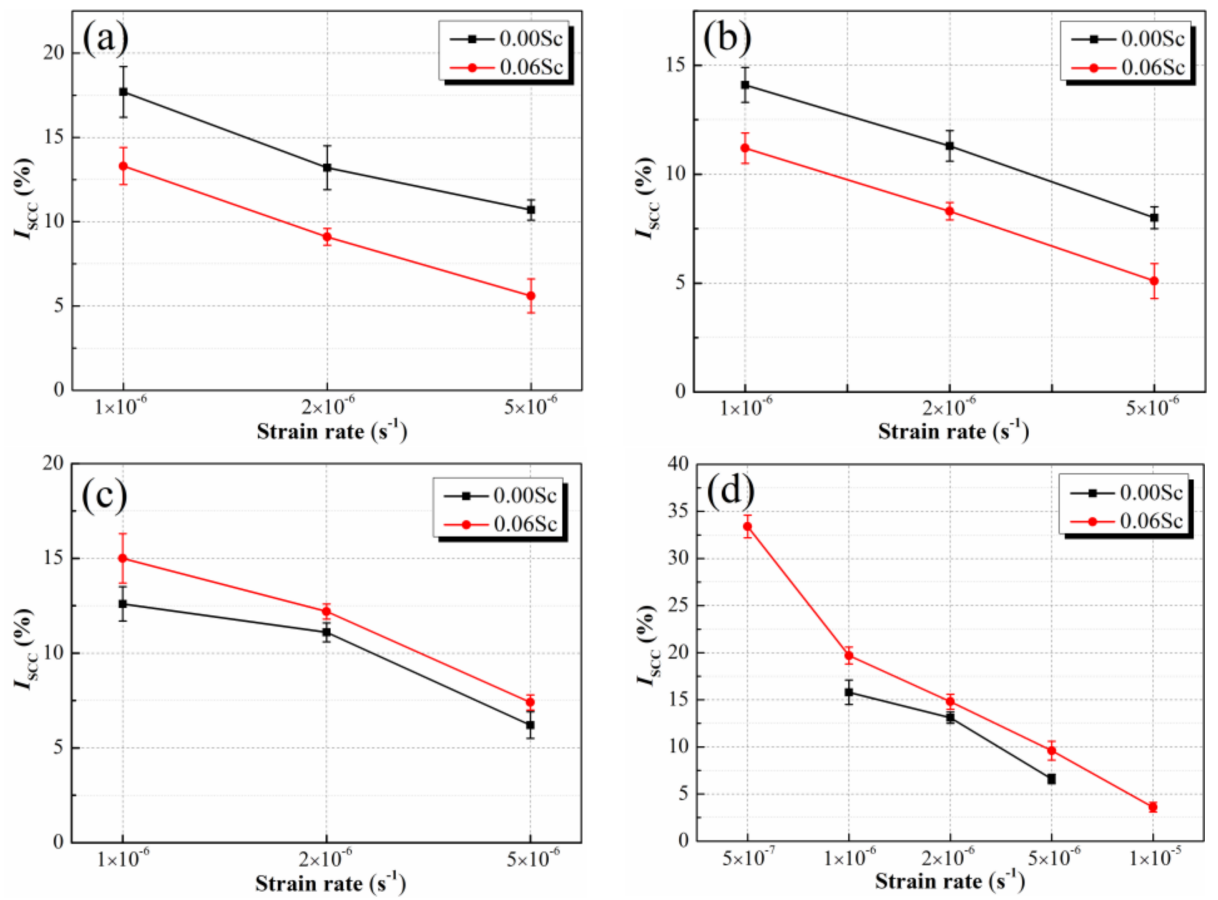

Figure 6. SCC susceptibilities of two aged alloys at different strain rate in acid and alkaline solutions: (a) $\mathrm{pH} 1$; (b) $\mathrm{pH} 3$; (c) $\mathrm{pH} 10$; (d) $\mathrm{pH} 12$.

\section{Discussion}

\subsection{Effect of Sc Addition on SCC Susceptibility of Al-Zn-Mg Alloy in Solution at Different $p H$}

The above analyses show that Sc addition can influence grain size and grain boundary microstructure of Al-Zn-Mg alloy (Figure 2). Grain refinement may change the corrosion behavior of the bulk material as a result of increasing the density of grain boundaries per unit volume [27]. Figure 7 shows polarization curves of two aged alloys in $3.5 \% \mathrm{NaCl}$ solution at different $\mathrm{pH}$. These polarization curves indicate that the shape of cathodic and anodic branches is similar for two aged alloys in a particular $\mathrm{pH}$ value of the solution. Corrosion current density $\left(I_{\text {corr }}\right)$ and corrosion potential $\left(E_{\text {corr }}\right)$ obtained from Figure 7 according to I/E Tafel slope analyses are displayed in Table 3.
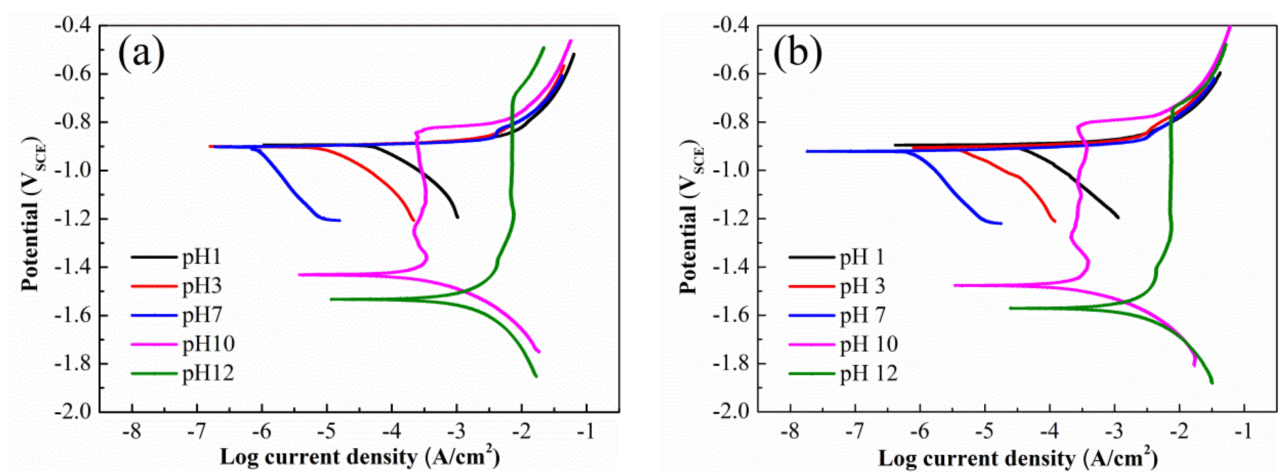

Figure 7. Polarization curves of two aged alloys in $3.5 \% \mathrm{NaCl}$ solution at different $\mathrm{pH}$ : (a) $0.00 \mathrm{Sc}$; (b) $0.06 \mathrm{Sc}$.

Compared with $3.5 \% \mathrm{NaCl}$ solution at $\mathrm{pH} 7, I_{\text {corr }}$ of two studied alloys both significantly increase with the enhancement of solution acidity, which is attributed to the aggravation of localized corrosion 
(Figure 4). In contrast, in neutral and acidic solutions, Sc addition reduces the $I_{\text {corr }}$ of Al-Zn-Mg alloy, thus decreases the surface corrosion.

For 0.06Sc alloy exposed in aqueous solution, $\mathrm{Sc}$ from solid solution and nano-sized $\mathrm{Al}_{3}(\mathrm{Sc}, \mathrm{Zr})$ phase can reacts with oxygen to give $\mathrm{Sc}_{2} \mathrm{O}_{3}$ accumulating on alloy surface. This promotes the formation of a dense and less aluminum oxyhydroxides between matrix and hydrated $\mathrm{Sc}_{2} \mathrm{O}_{3}$ layer [28], thereby enhances the localized corrosion resistance of $0.06 \mathrm{Sc}$ alloy in neutral solution. Santamaria et al. [29] confirmed that the formation of a protective hydrated $\mathrm{Sc}_{2} \mathrm{O}_{3}$ film on pure $\mathrm{Sc}$ in a slightly alkaline solution at $\mathrm{pH}$ 9. According to the Pourbaix diagram of $\mathrm{Sc}_{\mathrm{c}} \mathrm{H}_{2} \mathrm{O}$ system at room temperature [30], $\mathrm{Sc}$ from alloy surface forms aqueous $\mathrm{Sc}^{3+}$ in acid solution at $\mathrm{pH}<5$. Therefore, grain refinement caused by Sc addition is responsible for the reduction of localized corrosion on $\mathrm{Al}-\mathrm{Zn}-\mathrm{Mg}$ alloy surface in solution at $\mathrm{pH} 1$ and $\mathrm{pH} 3$. (Figure 4), which hinders the initiation of SCC crack. Furthermore, $\mathrm{SCC}$ behavior is closely related to grain boundary microstructure. GBPs of $\mathrm{Al}-\mathrm{Zn}-\mathrm{Mg}$ alloy are always anodic to the surrounding matrix, leading to the preferred anodic dissolution of GBPs [31]. Sc addition transforms GBPs from continuous distribution into interrupted distribution, which cuts continuous anode channel for SCC crack propagation. Sc addition can also decrease the width of PFZ, leading to small difference in electrochemical property between the grain boundary area and the grain interior, thus prevent a partial anodic reaction [18]. Garcia-Garcia et al. [32] reported that the surfaces of $\mathrm{Al}$ and its alloys in acid solution supported by a relatively thick passive film did not allow hydrogen evolution, thus the amount of hydrogen absorbed into the matrix from neutral or acidic solution is negligible. As a result, in 3.5\% NaCl solution at $\mathrm{pH} 1, \mathrm{pH} 3$ and $\mathrm{pH} 7$, Sc addition reduces SCC susceptibility of $\mathrm{Al}-\mathrm{Zn}-\mathrm{Mg}$ alloy.

Table 3. Electrochemical parameters obtained from I/E Tafel slope analyses from Figure 7.

\begin{tabular}{ccccc}
\hline \multirow{2}{*}{ Solution pH } & \multicolumn{2}{c}{$\boldsymbol{I}_{\text {corr }}\left(\boldsymbol{\mu} \mathbf{A} \cdot \mathbf{c m}^{-2}\right)$} & \multicolumn{2}{c}{$E_{\text {corr }}\left(\mathbf{V}_{\text {SCE }}\right)$} \\
\cline { 2 - 5 } & $\mathbf{0 . 0 0 S c}$ & $\mathbf{0 . 0 6 S c}$ & $\mathbf{0 . 0 0 S c}$ & .06Sc \\
\hline pH 1 & $66.073 \pm 0.675$ & $39.410 \pm 9.393$ & $-0.894 \pm 0.003$ & $-0.895 \pm 0.003$ \\
pH 3 & $11.078 \pm 1.375$ & $4.090 \pm 0.096$ & $-0.901 \pm 0.003$ & $-0.905 \pm 0.004$ \\
pH 7 & $0.901 \pm 0.008$ & $0.860 \pm 0.004$ & $-0.902 \pm 0.002$ & $-0.921 \pm 0.005$ \\
pH 10 & $253.219 \pm 16.878$ & $223.794 \pm 11.977$ & $-1.431 \pm 0.005$ & $-1.476 \pm 0.006$ \\
pH 12 & $1009.224 \pm 40.130$ & $1547.487 \pm 185.988$ & $-1.533 \pm 0.001$ & $-1.571 \pm 0.004$ \\
\hline
\end{tabular}

However, $\mathrm{Al}-\mathrm{Zn}-\mathrm{Mg}$ alloy dissolves faster in alkaline solution than in acid solution due to ready thinning of the passive film. In alkaline solution, the overall reaction is governed as follows [33]:

$$
\mathrm{Al}+3 \mathrm{H}_{2} \mathrm{O}+\mathrm{OH}^{-} \rightarrow \mathrm{Al}(\mathrm{OH})_{4}^{-}+\frac{3}{2} \mathrm{H}_{2} \uparrow .
$$

Hydrogen gas is produced by the reduction of $\mathrm{H}_{2} \mathrm{O}$. This appears to be rate-limited by the single electron transfer reaction:

$$
\mathrm{H}_{2} \mathrm{O}+\mathrm{e}^{-} \rightarrow \mathrm{H}_{\mathrm{ads}}+\mathrm{OH}^{-} \text {. }
$$

The adsorbed $\mathrm{H}$ atoms $\left(\mathrm{H}_{\mathrm{ads}}\right)$ at the metal-film interface can either combine to form $\mathrm{H}_{2}$ and bubble off, or can be absorbed into the $\alpha-\mathrm{Al}$ [34]. The generating rate of $\mathrm{H}_{\text {ads }}$ depends on corrosion rate of $\mathrm{Al}-\mathrm{Zn}-\mathrm{Mg}$ alloy in alkaline solution. In solution at $\mathrm{pH} \mathrm{10,} \mathrm{Sc} \mathrm{addition} \mathrm{slightly} \mathrm{reduces} \mathrm{the}$ $I_{\text {corr }}$ of Al-Zn-Mg alloy from $253.219 \mu \mathrm{A} \cdot \mathrm{cm}^{-2}$ to $223.794 \mu \mathrm{A} \cdot \mathrm{cm}^{-2}$. In solution at $\mathrm{pH} 12$, Sc addition sharply increases the $I_{\text {corr }}$ of Al-Zn-Mg alloy from $1009.224 \mu \mathrm{A} \cdot \mathrm{cm}^{-2}$ to $1547.487 \mu \mathrm{A} \cdot \mathrm{cm}^{-2}$. Moreover, it should be noted that $\mathrm{Sc}$ addition significantly reduces grain size of $\mathrm{Al}-\mathrm{Zn}-\mathrm{Mg}$ alloy, while hydrogen diffusivity is related to the grain size. Argade et al. [35] reported the grain size relationship with room temperature diffusivity:

$$
D_{\mathrm{H}}=0.00124 \cdot d^{-1.96},
$$

where $D_{\mathrm{H}}$ is hydrogen diffusivity in $\mathrm{Al}$ matrix at room temperature and $d$ is the average grain size. Therefore, grain refinement obviously promotes the diffusion of $\mathrm{H}_{\text {ads }}$ at the metal-film interface into 
the matrix, leading to a large amount of hydrogen atoms diffused into the 0.06Sc alloy in alkaline solution during SSRT process. Under the action of stress gradient, hydrogen atom will diffuse into high stress region through stress induced diffusion. During SSRT process, the absorbed $\mathrm{H}$ atoms are transported into corrosion crack tip by mobile dislocations and grain boundaries [36]. The segregation of hydrogen at corrosion crack tip weakens substrate interatomic bonds and promotes dislocation emission [37], accelerating SCC crack propagation. As a result, in $3.5 \% \mathrm{NaCl}$ solution at $\mathrm{pH} 10$ and $\mathrm{pH} 12$, Sc addition increases SCC susceptibility of Al-Zn-Mg alloy.

\subsection{Effect of Sc Addition on SCC Susceptibility of Al-Zn-Mg Alloy at Different Strain Rate}

Surface corrosion of the alloy in corrosive environment needs a certain incubation period. High strain rate $\left(1 \times 10^{-5} \mathrm{~s}^{-1}\right)$ results in the insufficient interaction between $\mathrm{Al}-\mathrm{Zn}-\mathrm{Mg}$ alloy and corrosive solution. In such case, fractures of two aged alloys are less caused by stress corrosion cracking, and mainly dominated by mechanical fracture. At slow strain rate $\left(5 \times 10^{-7} \mathrm{~s}^{-1}\right)$, the interaction of alloy surface and corrosive solution is sufficient, but corrosion crack tips may remain essentially protective films due to the crack tip strain rate is slow compared with the repassivation rate of bare surface [26], which hinders SCC crack growth and makes two aged alloys show low SCC susceptibility. Figure 8 gives surface morphologies of SSRT specimens failed at different strain rate in $3.5 \% \mathrm{NaCl}$ solution at $\mathrm{pH}$ 7. It can be found that reducing strain rate significantly aggravates the degree of localized corrosion of 0.00Sc alloy (Figure 8a,b), which promotes the initiation of corrosion crack. But the decrease of strain rate also increases the available time for repassivation of bare surface, and thus inhibit propagation of SCC crack. Interaction of the above two factors makes 0.00Sc alloy in neutral $3.5 \% \mathrm{NaCl}$ solution display relatively large SCC susceptibility in the strain rate range of $1 \times 10^{-6}-8 \times 10^{-6} \mathrm{~s}^{-1}$. However, the degree of localized corrosion of $0.06 \mathrm{Sc}$ alloy only slightly increases with the decrease of strain rate (Figure $8 c, d$ ), so the variation of strain rate has less influence on the initiation of corrosion crack. As a result, Sc addition can reduce the susceptible strain rate range to SCC of Al-Zn-Mg alloy.
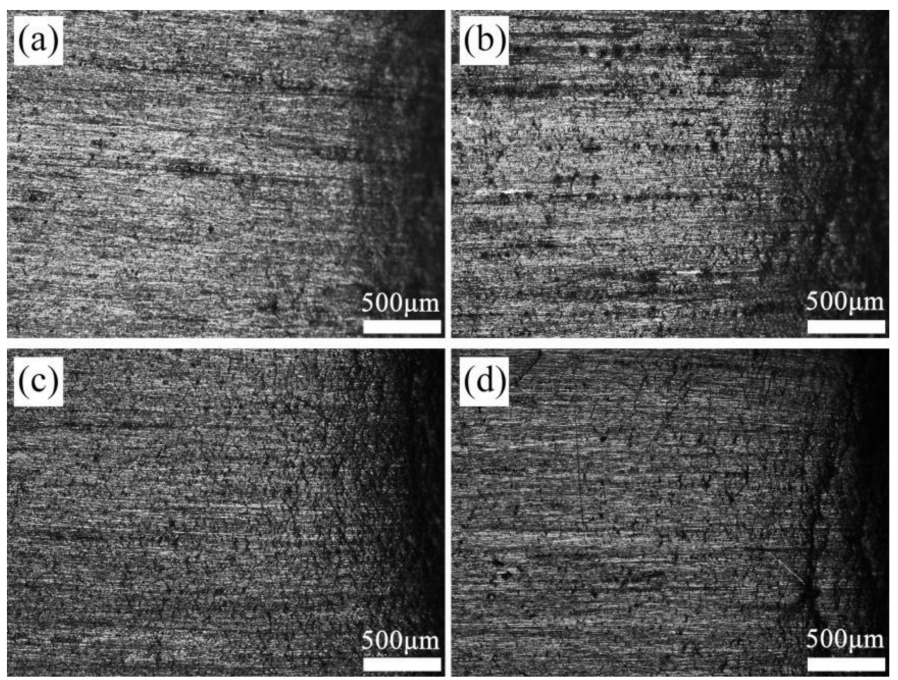

Figure 8. Surface morphologies of two aged alloys failed at different strain rate in $3.5 \% \mathrm{NaCl}$ solution at pH 7: (a) $0.00 \mathrm{Sc}, 2 \times 10^{-6} \mathrm{~s}^{-1}$; (b) $0.00 \mathrm{Sc}, 1 \times 10^{-6} \mathrm{~s}^{-1}$; (c) $0.06 \mathrm{Sc}, 2 \times 10^{-6} \mathrm{~s}^{-1}$; (d) $0.06 \mathrm{Sc}, 1 \times 10^{-6} \mathrm{~s}^{-1}$.

Compared with neutral solution, $\mathrm{Al}-\mathrm{Zn}-\mathrm{Mg}$ alloy in acid solution occurs more severe local corrosion. The degree of localized corrosion for two aged alloys both sharply increase by reducing strain rate (Figure 9). This indicates that the decrease of strain rate obviously promotes corrosion crack initiation of two aged alloys in acid solution, leading to a monotonical increase of SCC susceptibility. Besides, Sc addition enhances the resistance to localized corrosion of Al-Zn-Mg alloy surface in acid 
solution at different strain rate (Figure 9), and optimizes grain boundary microstructure (Figure 2), thus reduces SCC susceptibility of $\mathrm{Al}-\mathrm{Zn}-\mathrm{Mg}$ alloy at different strain rate. However, $\mathrm{Al}-\mathrm{Zn}-\mathrm{Mg}$ alloy in alkaline solution happens uniform corrosion (Figure 4), reducing strain rate do not aggravate the degree of localized corrosion, but a large amount of hydrogen atoms generated by reduction reaction can be absorbed into the matrix during SSRT process. Diffusion and penetration of the absorbed hydrogen from the surface into the interior of $\mathrm{Al}-\mathrm{Zn}-\mathrm{Mg}$ alloy are time-dependent, which is due to the slow diffusivity of hydrogen in solid $\mathrm{Al}$ (the diffusion coefficient is $1.75 \times 10^{-8} \mathrm{~m}^{2} / \mathrm{s}$ [38]). With the decrease of strain rate, the time available for substantial hydrogen entry and segregation becomes more sufficient. Taking $0.06 \mathrm{Sc}$ alloy as an example, at different strain rate, the hydrogen concentration near fracture location of the alloy in $3.5 \% \mathrm{NaCl}$ solution at $\mathrm{pH} 12$ is shown in Figure 10. It can be seen that the amount of hydrogen atoms diffused into the matrix significantly increase with the decrease of strain rate, and hydrogen concentration can reach $70 \mathrm{ppm}$ at a strain rate of $5 \times 10^{-7} \mathrm{~s}^{-1}$. Due to the improvement of hydrogen enhanced corrosion cracking effect, SCC susceptibilities of two aged alloys in alkaline solution both increase with the decrease of strain rate. In addition, although Sc addition optimizes grain boundary microstructure, grain refinement significantly promotes diffusion of hydrogen atoms into matrix, aggravating the SCC crack propagation. As a result, Sc addition increases SCC susceptibility of Al-Zn-Mg alloy in alkaline solution at different strain rate.
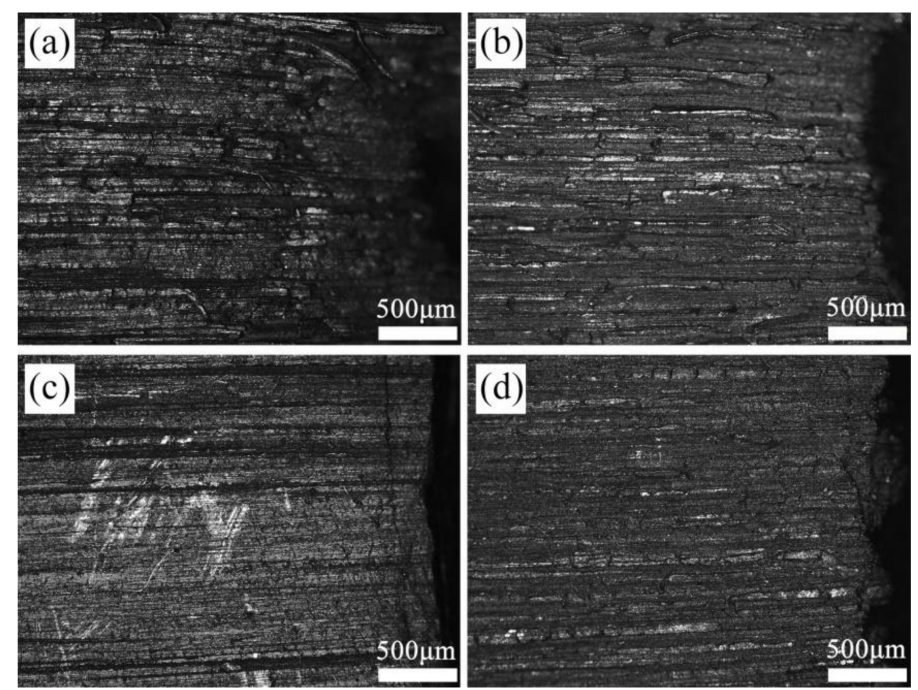

Figure 9. Surface morphologies of two aged alloys failed at different strain rate in $3.5 \% \mathrm{NaCl}$ solution at pH 1: (a) $0.00 \mathrm{Sc}, 2 \times 10^{-6} \mathrm{~s}^{-1}$; (b) $0.00 \mathrm{Sc}, 1 \times 10^{-6} \mathrm{~s}^{-1}$; (c) $0.06 \mathrm{Sc}, 2 \times 10^{-6} \mathrm{~s}^{-1}$; (d) $0.06 \mathrm{Sc}, 1 \times 10^{-6} \mathrm{~s}^{-1}$.

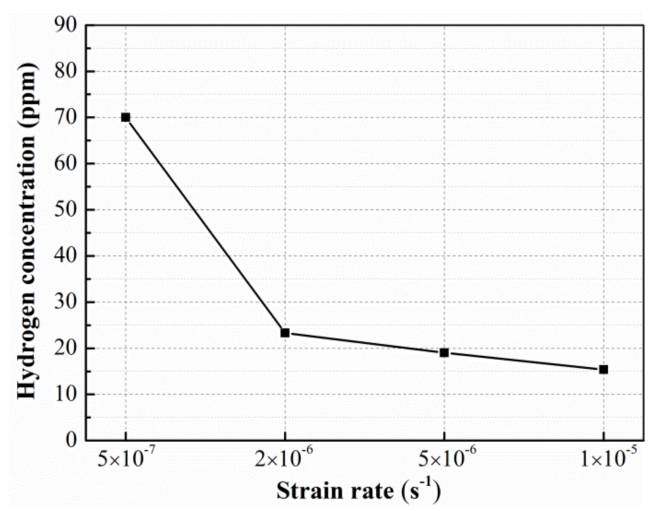

Figure 10. Hydrogen concentration near fracture location of $0.06 \mathrm{Sc}$ alloy tested at different strain rate in $3.5 \% \mathrm{NaCl}$ solution at $\mathrm{pH} 12$. 


\section{Conclusions}

1. Sc addition reduces grain size and width of PFZ, and transforms GBPs from continuous distribution into interrupted distribution by inhibiting recrystallization.

2. In neutral and acid 3.5\% NaCl solution, Sc addition hinders SCC crack initiation and growth, thus reduces SCC susceptibility of $\mathrm{Al}-\mathrm{Zn}-\mathrm{Mg}$ alloy. However, in alkaline $3.5 \% \mathrm{NaCl}$ solution, hydrogen atoms generated by reduction reaction can be absorbed into the matrix during SSRT process. Grain refinement significantly promotes the diffusion of hydrogen atoms into matrix, thus Sc addition increases SCC susceptibility of Al-Zn-Mg alloy.

3. Sc addition can reduce the relatively susceptible strain rate range to SCC of Al- $\mathrm{Zn}-\mathrm{Mg}$ alloy due to the improved resistance to localized corrosion of alloy surface in neutral $3.5 \% \mathrm{NaCl}$ solution.

4. In acidic $3.5 \% \mathrm{NaCl}$ solution, reducing strain rate sharply aggravates the degree of localized corrosion of alloy surface, thus increases SCC susceptibilities of two aged alloys, and Sc addition reduces SCC susceptibility of $\mathrm{Al}-\mathrm{Zn}-\mathrm{Mg}$ alloy at different strain rate. However, in alkaline 3.5\% $\mathrm{NaCl}$ solution, reducing strain rate increases the time available for substantial hydrogen entry and segregation, resulting in the increase of SCC susceptibilities of two aged alloys, and Sc addition increases SCC susceptibility of Al-Zn-Mg alloy at different strain rate due to grain refinement.

Acknowledgments: This work was supported by the State's Key Project of Research and Development [Grant numbers 2016YFB1200600]; and the Strategic Priority Program of the Chinese Academy of Sciences [Grant numbers XDB22000000].

Author Contributions: Haichang Jiang and Lijian Rong conceived and designed the experiments; Desheng Yan contributed the preparation of materials. Zhaoming Li performed the experiments and wrote the paper.

Conflicts of Interest: The authors declare no conflict of interest.

\section{References}

1. He, J.L.; Zhang, D.T.; Zhang, W.W.; Qiu, C.; Zhang, W. Constitutive equation and hot compression deformation behavior of homogenized Al-7.5Zn-1.5Mg-0.2Cu- $0.2 \mathrm{Zr}$ alloy. Materials 2017, 10, 1193. [CrossRef] [PubMed]

2. Sheng, X.F.; Lei, Q.; Xiao, Z.; Wang, M.P. Precipitation behavior and quenching sensitivity of a spray deposited Al-Zn-Mg-Cu-Zr alloy. Materials 2017, 10, 1100. [CrossRef] [PubMed]

3. Deschamps, A.; Ringeval, S.; Texier, G.; Delfaut-Durut, L. Quantitative characterization of the microstructure of an electron-beam welded medium strength Al-Zn-Mg alloy. Mater. Sci. Eng. A 2009, 517, 361-368. [CrossRef]

4. Shi, C.J.; Lai, J.; Chen, X.G. Microstructural evolution and dynamic softening mechanisms of Al-Zn-Mg-Cu alloy during hot compressive deformation. Materials 2014, 7, 244-264. [CrossRef] [PubMed]

5. Yang, H.H.; Wang, X.S.; Wang, Y.M.; Wang, Y.L.; Zhang, Z.H. Microarc oxidation coating combined with surface pore-sealing treatment enhances corrosion fatigue performance of 7075-T7351 Al alloy in different media. Materials 2017, 10, 609. [CrossRef] [PubMed]

6. Harding, M.D.; Donaldson, I.W.; Junior, R.L.H.; Bishop, D.P. Effects of post-sinter processing on an Al-Zn-Mg-Cu powder metallurgy alloy. Metals 2017, 7, 370. [CrossRef]

7. Qin, C.; Gou, G.Q.; Che, X.L.; Chen, H.; Chen, J.; Li, P.; Gao, W. Effect of composition on tensile properties and fracture toughness of Al-Zn-Mg alloy (A7N01S-T5) used in high speed trains. Mater. Des. 2016, 91, 278-285. [CrossRef]

8. Liu, J.; Yao, P.; Zhao, N.; Shi, C.; Li, H.; Li, X.; Xi, D.; Yang, S. Effect of minor Sc and Zr on recrystallization behavior and mechanical properties of novel Al-Zn-Mg-Cu alloys. J. Alloy. Compd. 2016, 657, 717-725. [CrossRef]

9. Chen, S.Y.; Chen, K.H.; Dong, P.X.; Ye, S.P.; Huang, L.P. Effect of recrystallization and heat treatment on strength and SCC of an Al-Zn-Mg-Cu alloy. J. Alloy. Compd. 2013, 581, 705-709. [CrossRef]

10. Xu, Y.Q.; Zhan, L.H. Effect of creep aging process on microstructures and properties of the retrogressed Al-Zn-Mg-Cu alloy. Metals 2016, 6, 189. [CrossRef] 
11. Kurt, H.I.; Oduncuoglu, M.; Kurt, M. A mathematical formulation to estimate the effect of grain refiners on the ultimate tensile strength of Al-Zn-Mg-Cu alloys. Metals 2015, 5, 836-849. [CrossRef]

12. Liu, C.; Liu, Y.L.; Ma, L.Y.; Yi, J.H. Effects of solution treatment on microstructure and high-cycle fatigue properties of 7075 aluminum alloy. Metals 2017, 7, 193. [CrossRef]

13. Minoda, T.; Yoshida, H. Effect of grain boundary characteristics on intergranular corrosion resistance of 6061 aluminum alloy extrusion. Metall. Mater. Trans. A 2002, 33, 2891-2898. [CrossRef]

14. Shi, Y.J.; Pan, Q.L.; Li, M.J.; Huang, X.; Li, B. Effect of Sc and Zr additions on corrosion behaviour of Al-Zn-Mg-Cu alloys. J. Alloy. Compd. 2014, 612, 42-50. [CrossRef]

15. Fang, H.C.; Chen, K.H.; Chen, X.; Chao, H.; Peng, G.S. Effect of $\mathrm{Cr}$, $\mathrm{Yb}$ and $\mathrm{Zr}$ additions on localized corrosion of Al-Zn-Mg-Cu alloy. Corros. Sci. 2009, 51, 2872-2877. [CrossRef]

16. Shi, Y.J.; Pan, Q.L.; Li, M.J.; Huang, X.; Li, B. Influence of alloyed Sc and Zr, and heat treatment on microstructures and stress corrosion cracking of Al-Zn-Mg-Cu alloys. Mater. Sci. Eng. A 2015, 621, 173-181. [CrossRef]

17. Kannan, M.B.; Raja, V.S. Enhancing stress corrosion cracking resistance in Al-Zn-Mg-Cu-Zr alloy through inhibiting recrystallization. Eng. Fract. Mech. 2010, 77, 249-256. [CrossRef]

18. Deng, Y.; Yin, Z.M.; Zhao, K.; Duan, J.Q.; Hu, J.; He, Z.B. Effects of Sc and Zr microalloying additions and aging time at 120 degrees $C$ on the corrosion behaviour of an Al-Zn-Mg alloy. Corros. Sci. 2012, 65, 288-298. [CrossRef]

19. Huang, X.; Pan, Q.L.; Li, B.; Liu, Z.M.; Huang, Z.Q.; Yin, Z.M. Microstructure, mechanical properties and stress corrosion cracking of Al-Zn-Mg-Zr alloy sheet with trace amount of Sc. J. Alloy. Compd. 2015, 650, 805-820. [CrossRef]

20. Kannan, M.B.; Raja, V.S.; Mukhopadhyay, A.K.; Schmuki, P. Environmentally assisted cracking behavior of peak-aged 7010 aluminum alloy containing scandium. Metall. Mater. Trans. A 2005, 36, 3257-3262. [CrossRef]

21. Deng, Y.; Yin, Z.M.; Zhao, K.; Duan, J.Q.; Hu, J.; He, Z.B. Effects of Sc and Zr microalloying additions on the microstructure and mechanical properties of new Al-Zn-Mg alloys. J. Alloy. Compd. 2012, 530, 71-80. [CrossRef]

22. Li, G.; Zhao, N.Q.; Liu, T.; Li, J.J.; He, C.N.; Shi, C.S.; Liu, E.Z.; Sha, J.W. Effect of Sc/Zr ratio on the microstructure and mechanical properties of new type of Al-Zn-Mg-Sc-Zr alloys. Mater. Sci. Eng. A 2014, 617, 219-227. [CrossRef]

23. Tsai, W.T.; Duh, J.B.; Yeh, J.J.; Lee, J.T.; Chang, Y.C. Effect of pH on stress corrosion cracking of 7050-T7451 aluminum alloy in $3.5 \mathrm{wt} \% \mathrm{NaCl}$ solution. Corrosion 1990, 46, 444-449. [CrossRef]

24. Rout, P.K.; Ghosh, M.M.; Ghosh, K.S. Effect of solution pH on electrochemical and stress corrosion cracking behaviour of a 7150 Al-Zn-Mg-Cu alloy. Mater. Sci. Eng. A 2014, 604, 156-165. [CrossRef]

25. Deschamps, A.; Texier, G.; Ringeval, S.; Delfaut-Durut, L. Influence of cooling rate on the precipitation microstructure in a medium strength Al-Zn-Mg alloy. Mater. Sci. Eng. A 2009, 501, 133-139. [CrossRef]

26. Wloka, J.; Virtanen, S. Influence of scandium on the pitting behaviour of Al-Zn-Mg-Cu alloys. Acta. Mater. 2007, 55, 6666-6672. [CrossRef]

27. Ralston, K.D.; Birbilis, N.; Davies, C.H.J. Revealing the relationship between grain size and corrosion rate of metals. Scr. Mater. 2010, 63, 1201-1204. [CrossRef]

28. Ganiev, I.N. Corrosion-electrochemical behavior of special-purity aluminum and its AK1 alloy alloyed with Scandium. Russ. J. Appl. Chem. 2004, 77, 925-929. [CrossRef]

29. Santamaria, M.; Muratore, F.; Di Quarto, F. Growth and characterization of anodic films on Scandium. J. Electrochem. Soc. 2014, 161, C36-C41. [CrossRef]

30. Pourbaix, M. Atlas of Electrochemical Equilibria in Aqueous Solutions, 2nd ed.; National Association of Corrosion Engineers: Houston, TX, USA, 1974; pp. 177-182.

31. Sun, X.Y.; Zhang, B.; Lin, H.Q.; Zhou, Y.; Sun, L.; Wang, J.Q.; Han, E.H.; Ke, W. Correlations between stress corrosion cracking susceptibility and grain boundary microstructures for an Al-Zn-Mg alloy. Corros. Sci. 2013, 77, 103-112. [CrossRef]

32. Garcia-Garcia, F.J.; Skeldon, P.; Thompson, G.E.; Smithc, G.C. The effect of nickel on alloy microstructure and electrochemical behaviour of AA1050 aluminium alloy in acid and alkaline solutions. Electrochim. Acta 2012, 75, 229-238. [CrossRef]

33. Boukerche, I.; Djerad, S.; Benmansour, L.; Tifouti, L.; Saleh, K. Degradability of aluminum in acidic and alkaline solutions. Corros. Sci. 2014, 78, 343-352. [CrossRef] 
34. Najjar, D.; Magnin, T.; Warner, T.J. Influence of critical surface defects and localized competition between anodic dissolution and hydrogen effects during stress corrosion cracking of a 7050 aluminium alloy. Mater. Sci. Eng. A 1997, 238, 293-302. [CrossRef]

35. Argade, G.R.; Kumar, N.; Mishra, R.S. Stress corrosion cracking susceptibility of ultrafine grained Al-Mg-Sc alloy. Mater. Sci. Eng. A 2013, 565, 80-89. [CrossRef]

36. Albrecht, J.; Bernstein, I.M.; Thompson, A.W. Evidence for dislocation transport of hydrogen in aluminum. Metall. Mater. Trans. A 1982, 13, 811-820. [CrossRef]

37. Lynch, S. Mechanistic and fractographic aspects of stress corrosion cracking. Corros. Rev. 2012, 30, 63-104. [CrossRef]

38. Young, G.A.; Scully, J.R. The diffusion and trapping of hydrogen in high purity aluminum. Acta Mater. 1998, 46, 6337-6349. [CrossRef]

(C) 2018 by the authors. Licensee MDPI, Basel, Switzerland. This article is an open access article distributed under the terms and conditions of the Creative Commons Attribution (CC BY) license (http://creativecommons.org/licenses/by/4.0/). 